\title{
Green Mold Diseases of Agaricus and Pleurotus spp. Are Caused by Related but Phylogenetically Different Trichoderma Species
}

\author{
L. Hatvani, Z. Antal, L. Manczinger, A. Szekeres, I. S. Druzhinina, \\ C. P. Kubicek, A. Nagy, E. Nagy, C. Vágvölgyi, and L. Kredics
}

First, third, fourth, and ninth authors: Department of Microbiology, Faculty of Sciences, University of Szeged, Közép fasor 52, H-6726 Szeged, Hungary; second, eighth, and tenth authors: Microbiological Research Group, Hungarian Academy of Sciences and University of Szeged, Közép fasor 52, H-6726 Szeged, Hungary; fifth and sixth authors: Research Area Gene Technology and Applied Biochemistry, Institute of Chemical Engineering, Vienna University of Technology, Getreidemarkt 9/166.5, A-1060 Vienna, Austria; and seventh author: Pilze-Nagy Ltd., P.O. Box 407, H-6001 Kecskemét, Hungary.

Accepted for publication 18 October 2006.

\begin{abstract}
Hatvani, L., Antal, Z., Manczinger, L., Szekeres, A., Druzhinina, I. S., Kubicek, C. P., Nagy, A., Nagy, E., Vágvölgyi, C., and Kredics, L. 2007. Green mold diseases of Agaricus and Pleurotus spp. are caused by related but phylogenetically different Trichoderma species. Phytopathology 97:532-537.

Producers of champignon (Agaricus bisporus) and oyster mushroom (Pleurotus ostreatus) are facing recent incidents of green mold epidemics in Hungary. We examined 66 Trichoderma strains isolated from Agaricus compost and Pleurotus substrate samples from three Hungarian mushroom producing companies by a polymerase chain reaction-based diagnostic test for $T$. aggressivum, sequence analysis of the internal transcribed spacer region 1 (ITS1) and ITS2 and (selectively) of the fourth and fifth intron of translation elongation factor $1 \alpha(t e f 1 \alpha)$, and restriction fragment length polymorphism of mitochondrial DNA. Seven Trichoderma species were identified: T. aggressivum f. europaeum (17

isolates), T. harzianum (three isolates), T. longibrachiatum (four isolates), T. ghanense (one isolate), T. asperellum (four isolates), T. atroviride (nine isolates), and a still undescribed phylogenetic species, Trichoderma sp. DAOM 175924 (28 isolates). T. aggressivum f. europaeum was exclusively derived from A. bisporus compost, whereas Trichoderma sp. DAOM 175924 exclusively occurred in the substrate for Pleurotus cultivation. Sequences of the latter strains were co-specific with those for Trichoderma pathogens of $P$. ostreatus in Korea. The widespread occurrence of this new species raises questions as to why infections by it have just only recently been observed. Our data document that (i) green mold disease by $T$. aggressivum f. europaeum has geographically expanded to Central Europe; (ii) the green mold disease of P. ostreatus in Hungary is due to the same Trichoderma species as in Korea and the worldwide distribution of the new species indicates the possibility of spreading epidemics; and (iii) on mushroom farms, the two species are specialized on their different substrates.
\end{abstract}

Worldwide mushroom cultivation is dominated by the production of Agaricus bisporus, Lentinula edodes, and Pleurotus ostreatus (5). For the first, the association of Trichoderma species with the respective compost has been known for a long time to limit commercial production (25). However, this problem became severe with the onset of green mold epidemic-or epimycoticin Northern Ireland in 1985, which was quickly succeeded by subsequent outbreaks in Ireland (1986), England and Scotland (1987), the Netherlands (1994), France (1997), and Spain (1998) $(10,15,17,18)$. In the early 1990 s, a similar disease appeared in mushroom crops in the United States and Canada $(4,19,20)$. The escalation of green mold evoked extensive research efforts to identify and study the causative agent. Although a number of Trichoderma spp. have been isolated from mushroom compost, aggressive colonization was shown to be exclusively due to two forma speciales of a new species of Trichoderma, viz. T. aggressivum f. europaeum in Europe and T. aggressivum f. aggressivum in North America (23), which have previously been described as T. harzianum biotypes 2 and 4 , respectively $(17,18)$.

In the last 2 years, outbreaks of Trichoderma green mold have also been reported to seriously affect the commercial production of $P$. ostreatus in Korea (21) and Italy (26). The causative agent appears to be distinct from T. aggressivum in morphological and

Corresponding author: L. Kredics; E-mail address: kredics@ bio.u-szeged.hu

doi:10.1094/PHYTO-97-4-0532

(c) 2007 The American Phytopathological Society cultural characters $(21,26)$. Park et al. (21) claimed that two different new species (T. koreana and T. pleuroti) are responsible for the epidemics on P. ostreatus in Korea, but unfortunately they did not document the data allowing this conclusion.

Hungary is one of the leading European nations for mushroom production and export (38,000 and 16,000 tons in the year 2000, respectively; source, Hungarian Vegetable and Fruit Board). Recently, Hungarian producers noticed the occurrence of a Trichoderma green mold problem in their mushroom farms both for $A$. bisporus and for $P$. ostreatus, suggesting the simultaneous emergence of aggressive Trichoderma strains. In the present study, we addressed the following questions arising from this situation. (i) Is the green mold disease of A. bisporus due to T. aggressivum f. europaeum, i.e., has the Western European epidemic now spread to Central Europe? (ii) Is the green mold disease of $P$. ostreatus in Hungary due to T. aggressivum or to the Trichoderma species reported from Korea? (iii) And are these two types of green mold specific for their substrates?

\section{MATERIALS AND METHODS}

Strains and culture conditions. Trichoderma strains were isolated from samples of compost and substrate used for A. bisporus and $P$. ostreatus cultivation from three Hungarian mushroom farms (referred to further as A, B, and C). Farm A produces $P$. ostreatus on wheat straw as substrate, while farm B produces A. bisporus on compost containing wheat straw, chicken manure, horse manure, and gypsum, supplemented with soya meal as an 
additive. Farm $\mathrm{C}$ produces both mushrooms on the corresponding substrates described above. Samples were put on plates containing solid yeast extract-glucose (YEG) medium (5 g of glucose per liter, $1 \mathrm{~g}$ of yeast extract per liter, $5 \mathrm{~g}$ of $\mathrm{KH}_{2} \mathrm{PO}_{4}$ per liter, and $20 \mathrm{~g}$ of agar per liter in distilled water supplemented with $0.1 \mathrm{~g}$ of streptomycin per liter and $0.1 \mathrm{~g}$ of chloramphenicol per liter). After the occurrence of conidiation, conidial suspensions were prepared, diluted, and plated on solid YEG medium. Agar plugs cut from separately growing young Trichoderma colonies were transferred to new plates with the same medium. The isolates were deposited in the strain collection of the University of Szeged, Hungary, and are available from the corresponding author.

Polymerase chain reaction-based identification of $T$. aggressivum. The diagnostic polymerase chain reaction (PCR) test for $T$. aggressivum developed by Chen et al. (6) was carried out with primers Th-F (5'-CGGTGACATCTGAAAAGTCGTG-3') and Th-
$\mathrm{R}$ (5'-TGTCACCCGTTCGGATCATCCG-3') in a T3 thermocycler (Biometra, Gottinger, Germany) with 1 cycle at $94^{\circ} \mathrm{C}$ for $2 \mathrm{~min}, 35$ cycles at $94^{\circ} \mathrm{C}$ for $15 \mathrm{~s}, 62^{\circ} \mathrm{C}$ for $30 \mathrm{~s}$, and $74^{\circ} \mathrm{C}$ for $30 \mathrm{~s}$, and a final elongation step at $72^{\circ} \mathrm{C}$ for $7 \mathrm{~min}$.

Amplification and sequence analysis of the ITS region and tef1. DNA isolation, PCR amplification of the internal transcribed spacer (ITS1-5.8S rDNA-ITS2) region, and automatic DNA sequencing of the fragments were carried out as described previously (22). A $0.7-\mathrm{kb}$ fragment of the translation elongation factor $1 \alpha$ (tef1), containing the fourth and fifth intron, was amplified by the primer pair EF1-728F (5'-CATCGAGAAGTTCGAGAAGG-3') and TEF-LLErev (5'-AACTTGCAGGCAATGTGG-3'). Amplification was performed in a T3 thermocycler as follows: 1 cycle at $94^{\circ} \mathrm{C}$ for $1 \mathrm{~min}, 30$ cycles at $94^{\circ} \mathrm{C}$ for $1 \mathrm{~min}$, $59^{\circ} \mathrm{C}$ for $1 \mathrm{~min}$, and $74^{\circ} \mathrm{C}$ for $50 \mathrm{~s}$, and a final elongation step at $74^{\circ} \mathrm{C}$ for $7 \mathrm{~min}$. Amplicon purification and sequencing was done

TABLE 1. Strains, sources of isolation, and GenBank accession numbers of internal transcribed spacer 1 (ITS1), ITS2, and tef1 sequences

\begin{tabular}{|c|c|c|c|c|c|}
\hline Strain & Source of isolation & Taxon & ITS1 & ITS2 & tef 1 \\
\hline \multicolumn{6}{|l|}{ CBS 450.95, CBS 100527, } \\
\hline \multicolumn{6}{|l|}{ CBS 100525, CBS 100526,} \\
\hline CBS 433.95, CBS 689.94 & Agaricus compost, United Kingdom & T. aggressivum f. europaeum & DQ328879 & DQ328903 & \\
\hline A03 & Pleurotus substrate, Farm A, Hungary & Trichoderma sp. DAOM 175924 & DQ328882a & DQ328912 & \\
\hline A06 & Pleurotus substrate, Farm A, Hungary & Trichoderma sp. DAOM 175924 & DQ328882a & DQ328911 & \\
\hline A08 & Pleurotus substrate, Farm A, Hungary & Trichoderma sp. DAOM 175924 & DQ328897 & DQ328939 & \\
\hline $\mathrm{A} 09, \mathrm{~A} 13, \mathrm{~A} 33$ & Pleurotus substrate, Farm A, Hungary & Trichoderma sp. DAOM 175924 & DQ328882 & DQ328907 & \\
\hline A11 & Pleurotus substrate, Farm A, Hungary & Trichoderma sp. DAOM 175924 & DQ328898 & DQ328939 & \\
\hline A14 & Pleurotus substrate, Farm A, Hungary & Trichoderma sp. DAOM 175924 & DQ328882 & DQ328913 & \\
\hline $\mathrm{A} 15, \mathrm{~A} 20, \mathrm{~A} 22, \mathrm{~A} 23, \mathrm{~A} 27, \mathrm{~A} 30, \mathrm{~A} 34$ & Pleurotus substrate, Farm A, Hungary & Trichoderma sp. DAOM 175924 & DQ328882 & DQ328915 & \\
\hline A16 & Pleurotus substrate, Farm A, Hungary & Trichoderma sp. DAOM 175924 & DQ328882 & DQ328906 & \\
\hline A18 & Pleurotus substrate, Farm A, Hungary & Trichoderma sp. DAOM 175924 & DQ328882 & DQ328914 & \\
\hline A19 & Pleurotus substrate, Farm A, Hungary & Trichoderma sp. DAOM 175924 & DQ328883 & DQ328906 & \\
\hline A 25 & Pleurotus substrate, Farm A, Hungary & Trichoderma sp. DAOM 175924 & DQ328898 & DQ328939 & \\
\hline A26 & Pleurotus substrate, Farm A, Hungary & Trichoderma sp. DAOM 175924 & DQ328888 & DQ328907 & \\
\hline A 28 & Pleurotus substrate, Farm A, Hungary & Trichoderma sp. DAOM 175924 & DQ328884 & DQ328907 & \\
\hline A29 & Pleurotus substrate, Farm A, Hungary & Trichoderma sp. DAOM 175924 & DQ328882 & DQ328916 & \\
\hline A 35 & Pleurotus substrate, Farm A, Hungary & T. longibrachiatum & DQ328902 & DQ328943 & DQ364636 \\
\hline A 37 & Pleurotus substrate, Farm A, Hungary & Trichoderma sp. DAOM 175924 & DQ328898 & DQ328940 & \\
\hline A 38 & Pleurotus substrate, Farm A, Hungary & T. asperellum & DQ328889 & DQ328917 & \\
\hline A39 & Pleurotus substrate, Farm A, Hungary & T. atroviride & DQ328890 & DQ328918 & \\
\hline B01 & Agaricus compost, Farm B, Hungary & T. aggressivum f. europaeum & DQ328892 & DQ328903 & \\
\hline B02 & Agaricus compost, Farm B, Hungary & T. aggressivum f. europaeum & DQ328899 & DQ328903 & \\
\hline B03, В04, В07, В12, В18, В31, В35 & Agaricus compost, Farm B, Hungary & T. aggressivum f. europaeum & DQ328879 & DQ328903 & \\
\hline B05 & Agaricus compost, Farm B, Hungary & T. aggressivum f. europaeum & DQ328879 & DQ328921 & \\
\hline B08 & Agaricus compost, Farm B, Hungary & T. aggressivum f. europaeum & DQ328900 & DQ328903 & \\
\hline B09 & Agaricus compost, Farm B, Hungary & T. aggressivum f. europaeum & DQ328879 & DQ328922 & \\
\hline B10 & Agaricus compost, Farm B, Hungary & T. aggressivum f. europaeum & DQ328879 & DQ328923 & \\
\hline B11 & Agaricus compost, Farm B, Hungary & T. aggressivum f. europaeum & DQ328893 & DQ328903 & \\
\hline B13 & Agaricus compost, Farm B, Hungary & T. aggressivum f. europaeum & DQ328879 & DQ328925 & \\
\hline B14 & Agaricus compost, Farm B, Hungary & T. ghanense & DQ328894 & DQ328924 & \\
\hline B15 & Agaricus compost, Farm B, Hungary & T. atroviride & DQ328885 & DQ328908 & \\
\hline B17 & Agaricus compost, Farm B, Hungary & T. longibrachiatum & DQ328886 & DQ328909 & DQ364633 \\
\hline B19 & Agaricus compost, Farm B, Hungary & T. longibrachiatum & DQ328902 & DQ328942 & DQ364634 \\
\hline B20 & Agaricus compost, Farm B, Hungary & T. atroviride & DQ328890 & DQ328926 & \\
\hline B21 & Agaricus compost, Farm B, Hungary & T. atroviride & DQ328890 & DQ328927 & \\
\hline B22 & Agaricus compost, Farm B, Hungary & T. atroviride & DQ328890 & DQ328929 & \\
\hline B23 & Agaricus compost, Farm B, Hungary & T. asperellum & DQ328889 & DQ328928 & \\
\hline B24 & Agaricus compost, Farm B, Hungary & T. atroviride & DQ328895 & DQ328930 & \\
\hline B26 & Agaricus compost, Farm B, Hungary & T. asperellum & DQ328889 & DQ328936 & \\
\hline B27 & Agaricus compost, Farm B, Hungary & T. atroviride & DQ328890 & DQ328931 & \\
\hline B28 & Agaricus compost, Farm B, Hungary & T. atroviride & DQ328890 & DQ328932 & \\
\hline B29 & Agaricus compost, Farm B, Hungary & T. longibrachiatum & DQ328887 & DQ328910 & DQ364635 \\
\hline B30 & Agaricus compost, Farm B, Hungary & T. atroviride & DQ328890 & DQ328933 & \\
\hline B32 & Agaricus compost, Farm B, Hungary & T. aggressivum f. europaeum & DQ328879 & DQ328934 & \\
\hline B34 & Agaricus compost, Farm B, Hungary & T. aggressivum f. europaeum & DQ328879 & DQ328935 & \\
\hline B37 & Agaricus compost, Farm B, Hungary & T. asperellum & DQ328889 & DQ328937 & \\
\hline $\mathrm{C} 01$ & Agaricus compost, Farm C, Hungary & T. harzianum & DQ328891 & DQ328919 & \\
\hline $\mathrm{C} 02$ & Pleurotus substrate, Farm C, Hungary & Trichoderma sp. DAOM 175924 & DQ328882 & DQ328920 & \\
\hline $\mathrm{C} 03$ & Pleurotus substrate, Farm C, Hungary & Trichoderma sp. DAOM 175924 & DQ328896 & DQ328938 & \\
\hline $\mathrm{C} 08$ & Agaricus compost, Farm C, Hungary & T. harzianum & DQ328901 & DQ328941 & \\
\hline $\mathrm{C} 15$ & Pleurotus substrate, Farm C, Hungary & Trichoderma sp. DAOM 175924 & DQ328898 & DQ328939 & \\
\hline $\mathrm{C} 22$ & Agaricus compost, Farm C, Hungary & T. harzianum & DQ328881 & DQ328905 & \\
\hline $\mathrm{C} 25, \mathrm{C} 27$ & Pleurotus substrate, Farm C, Hungary & Trichoderma sp. DAOM 175924 & DQ328897 & DQ328939 & \\
\hline
\end{tabular}

a Identical GenBank accession numbers indicate that the sequences of the corresponding isolates are identical. 
as described previously (13). All sequences obtained in this study have been submitted to NCBI GenBank and their accession numbers are indicated in Table 1.

Identification of Trichoderma at the species level. Sequence analysis of ITS1 and ITS2 and tef1 was performed with the aid of the programs TrichOKey 1.0 (8) and TrichoBLAST (12) available online by the International Subcommission on Trichoderma and Hypocrea Taxonomy.

Restriction fragment length polymorphism analysis of mitochondrial DNA. Restriction fragment length polymorphisms (RFLPs) of mitochondrial DNA (mtDNA) were generated with Hin6I as described by Antal et al. (2). The mtDNA profiles were converted to a similarity matrix and phylogenetic distances were calculated with the PhylTools software (3) to create a dendrogram by the unweighted pair group method with arithmetic means using the NEIGHBOR program of PHYLIP version 3.57 (9).

\section{RESULTS}

Identification of Trichoderma strains from Agaricus compost and Pleurotus substrate. A total of 66 Trichoderma isolates were isolated from compost and substrate samples from three different Hungarian mushroom growing companies: 26 from farm A (producing $P$. ostreatus), 32 from farm B (producing A. bisporus), and 8 from farm $\mathrm{C}$ (producing both of them). In order to obtain a quick balance of how many of them were T. aggressivum, a diagnostic PCR amplification test was performed with the specific primers Th-F and Th-R. This resulted in the tentative identification of 16 isolates as T. aggressivum (Fig. 1). However, several other isolates produced faint, yet detectable amplicons, rendering the result of this method uncertain. Therefore, fragments spanning the ITS1 and ITS2 sequences of the rRNA cluster were amplified, sequenced, and subjected to identification by the aid of TrichOKey and TrichoBLAST. This strategy identified 17 isolates as T. aggressivum, thereby confirming all of the identifications reported above and additionally including one isolate that gave only a faint band in the diagnostic assay (Fig. 1, B34). The other 49 Trichoderma strains were also identified by means of TrichOKey: they included T. harzianum (allele of the ex-type culture, three isolates), T. atroviride (nine isolates), T. asperellum (four isolates), and T. ghanense (one isolate). Four isolates belonged to the duplet of species T. longibrachiatum/ Hypocrea orientalis, which exhibits identical ITS1 and ITS2 sequences and cannot be differentiated further by TrichOKey. Similarity searches were therefore performed with their tef 1 sequences, which revealed that they belong to the clade of T. longibrachiatum. The remaining 27 strains were identified as a yet unnamed phylogenetic species of Trichoderma, Trichoderma sp. DAOM 175924. This preliminary denomination is based on a strain with the same ITS type isolated from decayed Acer stump in Ontario, Canada (13).

Distribution of Trichoderma species between Agaricus and Pleurotus substrates. The distribution of the identified species within the samples derived from cultivation of $A$. bisporus and $P$. ostreatus revealed an interesting pattern. T. aggressivum was exclusively isolated from A. bisporus compost, whereas Trichoderma sp. DAOM 175924 was exclusively found in the substrate for growth of $P$. ostreatus (Table 2). Other species were found only in minor proportions, although occurring at higher frequency on Agaricus compost. The compost for production of Agaricus at location $\mathrm{C}-\mathrm{a}$ farm with no significant $A$. bisporus losses due to Trichoderma sp.-was only contaminated by $T$. harzianum. These findings show that on mushroom farms there is a strict specificity of T. aggressivum and Trichoderma sp. DAOM 175924 for A. bisporus compost and $P$. ostreatus substrate, respectively, which is still maintained when the two basidiomycetes are cultivated in close geographic vicinity.

Trichoderma sp. DAOM 175924 is co-specific with the Pleurotus-pathogenic Trichoderma isolates from Korea. Having demonstrated that the occurrence of green mold in P. ostreatus substrate is due to a different Trichoderma species than that in Agaricus compost (T. aggressivum), we wondered whether Trichoderma sp. DAOM 175924 would be the same as one of the two species which have recently been reported to be the agent of Pleurotus disease in Korea (21). To this end, we retrieved the available ITS1 and ITS2 sequences for T. koreana and T. pleuroti (accession nos. DQ164405 to DQ164410) and submitted them to identification by TrichOKey and TrichoBLAST. All of these strains were identified as Trichoderma sp. DAOM 175924, and their sequence variation (1 nucleotide in ITS2) fell into the variation seen with other isolates of Trichoderma sp. DAOM 175924. We therefore conclude that the Pleurotus green mold isolates from Korea represent the same species as those found in the present study in Hungary.

Hungarian T. aggressivum isolates display the same mtDNA RFLP pattern as the early UK isolates. In order to learn whether the green mold outbreak observed in Hungary indeed results from spreading of the Western European Agaricus green mold epidemic, we compared the mtDNA RFLPs of the strains from this study with those of the T. aggressivum $\mathrm{f}$. europaeum isolates collected during the epidemic onset in Ire land and England in the late 1980s (24). This comparison showed that both populations share exactly the same RFLP pattern (Fig.

TABLE 2. Distribution of Trichoderma species in Hungarian Agaricus compost and Pleurotus substrate samples

\begin{tabular}{|c|c|c|c|c|c|}
\hline \multirow[b]{2}{*}{ Species } & \multicolumn{4}{|c|}{ Sample } & \multirow[b]{2}{*}{ Total } \\
\hline & $\begin{array}{c}\text { A } \\
\text { (Pleurotus } \\
\text { substrate) }\end{array}$ & $\begin{array}{c}\text { B } \\
\text { (Agaricus } \\
\text { compost) }\end{array}$ & $\begin{array}{c}\mathrm{C} / 1 \\
\text { (Pleurotus } \\
\text { substrate) }\end{array}$ & $\begin{array}{c}\mathrm{C} / 2 \\
\text { (Agaricus } \\
\text { compost) }\end{array}$ & \\
\hline T. harzianum & 0 & 0 & 0 & 3 & 3 \\
\hline \multicolumn{6}{|l|}{ Trichoderma sp. } \\
\hline DAOM 75924 & 23 & 0 & 5 & 0 & 28 \\
\hline T. aggressivum & 0 & 17 & 0 & 0 & 17 \\
\hline T. atroviride & 1 & 8 & 0 & 0 & 9 \\
\hline T. asperellum & 1 & 3 & 0 & 0 & 4 \\
\hline T. longibrachiatum & 1 & 3 & 0 & 0 & 4 \\
\hline T. ghanense & 0 & 1 & 0 & 0 & 1 \\
\hline Total & 26 & 32 & 5 & 3 & 66 \\
\hline
\end{tabular}

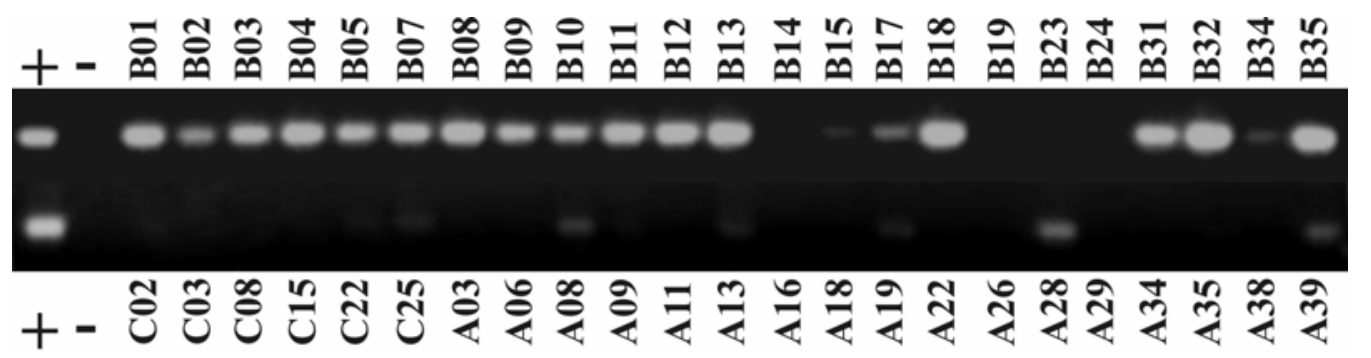

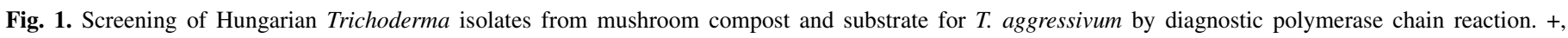
positive control (T. aggressivum f. europaeum CBS 100526); -, negative control without DNA. 
2A and C), which was clearly different from that of T. aggressivum f. aggressivum. For the latter, a common pattern could be observed apart from the small variance resulting from the presence or absence of a 2.2-kb band (Fig. 2A), the derivative of a DNase sensitive, S1 nuclease and RNase resistant plasmid of approximately $5.0 \mathrm{~kb}$, which was detected in the undigested DNA (data not shown).

Trichoderma sp. DAOM 175924 displays mtDNA RFLP heterogeneity. In contrast to $T$. aggressivum f. europaeum, isolates of Trichoderma sp. DAOM 175924 could be divided into three main distinct groups based on RFLPs of mtDNA (Fig. 2B and C). Samples from location A contained two of these groups, and $\mathrm{C}$, the third. In the course of this investigation, we also observed the presence of a plasmid-derived 2.2-kb band in some but not all isolates of Trichoderma sp. DAOM 175924 (Fig. 2B).

\section{DISCUSSION}

In this study, we performed a survey of Trichoderma spp. present in the substrates for commercial production of $A$. bisporus and $P$. ostreatus in Hungary. The data obtained for the former are in agreement with those of studies in Western Europe and the United States, i.e., that $T$. aggressivum is the major contaminant of Agaricus compost, but that some other species such as T. atroviride, T. asperellum, T. harzianum, and T. longibrachiatum can also be found in significant proportions (4). In contrast, and in

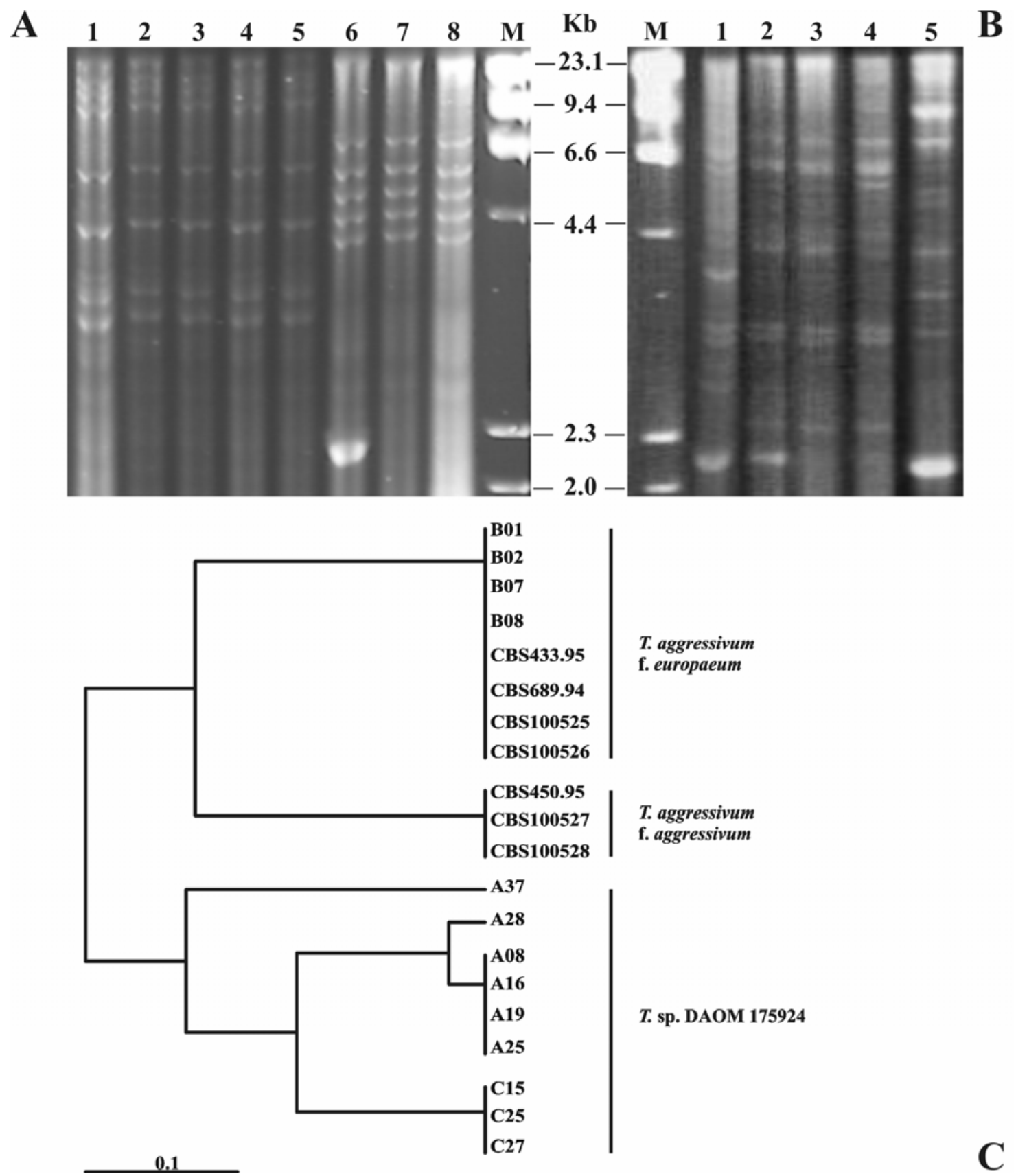

Fig. 2. Mitochondrial DNA polymorphism of Trichoderma aggressivum and Trichoderma sp. DAOM 175924 strains revealed by restriction fragment length polymorphism analysis with the restriction enzyme Hin6I. A, Lane 1, T. aggressivum f. europaeum B01; lane 2, T. aggressivum f. europaeum B07; lane 3, T. aggressivum f. europaeum B08; lane 4, T. aggressivum f. europaeum CBS 433.95; lane 5, T. aggressivum f. europaeum CBS 689.94; lane 6, T. aggressivum f. aggressivum CBS 450.95; lane 7, T. aggressivum f. aggressivum CBS 100528; lane 8, T. aggressivum f. aggressivum CBS 100527; and M, Lambda DNA/HindIII marker. B, Lane 1: Trichoderma sp. DAOM 175924 C15; lane 2, Trichoderma sp. DAOM 175924 A08; lane 3, Trichoderma sp. DAOM 175924 A16; lane 4, Trichoderma sp. DAOM 175924 A28; lane 5, Trichoderma sp. DAOM 175924 A37; and M, Lambda DNA/HindIII marker. C, Dendrogram of T. aggressivum and Trichoderma sp. DAOM 175924 strains based on their mtDNA profiles. The scale bar represents genetic distance. 
agreement with Park et al. (21), the substrate for oyster mushroom cultivation contained almost exclusively a new species of Trichoderma, the unnamed phylogenetic species Trichoderma sp. DAOM 175924. This indicates differences in the biology of these two Trichoderma pathogens, the latter apparently being a strong competitor of other Trichoderma spp. In fact, the Pleurotus green mold is known to be due to a heavy colonization and sporulation of Trichoderma spp. on the substrate, which ultimately inhibits growth of $P$. ostreatus.

There are further significant differences between $T$. aggressivum and Trichoderma sp. DAOM 175924: the former was so far isolated only from compost for production of A. bisporus, it was never observed in any field study. Seaby (24) speculated that red pepper mites may act as the vector for T. aggressivum. Such a mechanism of distribution would be consistent with the slow but steady migration of this infection within Europe and also within the United States, and with the fact that f. aggressivum and $\mathrm{f}$. europaeum still maintain their allopatric distribution, and renders the compost and the origin of its constituents a major source for the infection. In contrast, isolates of Trichoderma sp. DAOM 175924 have widely been found in soil or on decaying wood in the United States, Canada, New Zealand, Europe, India (I. S. Druzhinina and C. P. Kubicek, unpublished data), Iran (D. Zafari, personal communication), and China (27). The widespread occurrence of this new species raises the questions as to why infections by it have just only recently been observed and what makes this species specific for antagonizing just $P$. ostreatus. Interestingly, one of the Trichoderma sp. DAOM 175924 isolates (originally identified as "T. harzianum" HEND) is used in New Zealand as a biocontrol agent against Armillaria novae-zealandiae and Armillaria limonea on kiwifruit and pine, respectively (7).

Trichoderma sp. DAOM 175924 was originally misidentified as T. aureoviride (14), but molecular analyses proved it to be a new phylogenetic species that forms a sister group to T. harzianum and T. aggressivum (13). Park et al. (21) recently reported that the Korean Pleurotus green mold Trichoderma strains represent two distinct new species ( $T$. koreana and $T$. pleuroti), which can be distinguished by morphological characters, and sequences of ITS2, tef1, and a fragment of the rpb2 (RNA polymerase II subunit-encoding) gene. Unfortunately, their data and conclusions cannot be evaluated, as most of their sequences and all alignments and phylogenetic trees are unavailable. Only the ITS1-5.8S rDNA-ITS2 sequence of a few isolates could be found in GenBank (accession nos. DQ164405 to DQ164410), and their analysis by TrichOKey and TrichoBLAST showed that they were identical to isolates of Trichoderma sp. DAOM 175924. Park et al. (21) differentiated T. koreana and T. pleuroti on the basis of an $\mathrm{A} / \mathrm{C}$ transversion at position 447 in ITS2. The isolates from Hungary contain exclusively $\mathrm{C}$ at this position. Sequence analysis of another locus (tef 1 ) from several isolates of the $\mathrm{C}$ or A type strains also showed phylogenetically relevant nucleotide differences between these two groups of isolates (I. S. Druzhinina and C. P. Kubicek, unpublished data). However, because the names of the two putative species have not been published according to the rules for botanical nomenclature, and most of their gene sequences were not available during this study, we still maintain the designation Trichoderma sp. DAOM 175924 until the taxonomy of this species and its eventual split into two species has been clarified.

The analysis of mtDNA, due to its relatively small size and higher mutation rate in comparison with chromosomal DNA, is a powerful tool for differentiation of fungal isolates below the species level. mtDNA RFLP was used earlier to distinguish Trichoderma strains isolated from mushroom compost $(17,18)$. Here we applied this method to assess whether the Hungarian isolates of T. aggressivum f. europaeum belong to the same population as the first isolates from the British Islands, which started the epidemic. The results documented that there are no essential differences between the Hungarian isolates and the strains from Northern Ireland (CBS 433.95) and England (CBS 100525 and CBS 100526), while they all proved to be clearly different from T. aggressivum f. aggressivum isolates. This indicates that T. aggressivum f. europaeum has an essential clonal structure, and that the Hungarian strains likely have been derived from the Western European epidemic lineage. This report therefore indicates that the green mold epidemic of A. bisporus also has spread eastward to reach Central Europe.

In contrast to T. aggressivum, mtDNA RFLP of the isolates of Trichoderma sp. DAOM 175924 revealed at least four different RFLP patterns, three of which were even present in strains isolated from the same Pleurotus substrate (sample A), indicating that this species has a much higher genetic variability than T. aggressivum. It should be noted that this variability was observed within the ITS2 "C" type, and thus is not proof for the presence of two species within Trichoderma sp. DAOM 175924 as suggested by Park et al. (21). It will be interesting, however, to study whether there is a correlation between mtDNA RFLPs and the vigor of infection of Pleurotus substrates.

Interestingly, we also detected a plasmid in some but not all Hungarian isolates of Trichoderma sp. DAOM 175924. The occurrence of mitochondrial plasmids in Trichoderma spp. was reported for T. viride (16), T. aggressivum f. aggressivum (4), and T. harzianum $(1,4)$. In Fusarium oxysporum f. conglutinans, mitochondrial plasmids have been identified as one of the factors determining the host specificity (11). Further studies are necessary to determine whether the plasmids of Trichoderma sp. DAOM 175924 have any effect on its virulence to P. ostreatus.

In order to successfully combat the green mold problem, research efforts will be made to examine the physiology of isolates belonging to Trichoderma sp. DAOM 175924 and T. aggressivum f. europaeum, and to reveal the origin of contamination at mushroom farms, which could help the design of efficient control strategies and preventive measures.

\section{ACKNOWLEDGMENTS}

This study was supported by the Hungarian Government with research grant NKFP OM-00083/2004 by the Austrian-Hungarian bilateral grant WTZ HU 03/2007-Tet A02/2006 and by the Hungarian Scientific Research Fund (OTKA F68381). Work in the lab of I. S. Druzhinina and C. P. Kubicek was supported by the Austrian Science Foundation grant FWF P-16601. L. Kredics was supported by the János Bolyai Research Scholarship of the Hungarian Academy of Sciences.

\section{LITERATURE CITED}

1. Antal, Z., Manczinger, L., Kredics, L., Kevei, F., and Nagy, E. 2002. Complete DNA sequence and analysis of a mitochondrial plasmid in the mycoparasitic Trichoderma harzianum strain T95. Plasmid 47:148-152.

2. Antal, Z., Varga, J., Kredics, L., Szekeres, A., Hatvani, L., Manczinger, L., Vágvölgyi, C., and Nagy, E. 2006. Intraspecific mitochondrial DNA polymorphism within the emerging filamentous fungal pathogen Trichoderma longibrachiatum. J. Med. Microbiol. 55:31-35.

3. Buntjer, J. B. 1997. Phylogenetic computer tools (PhylTools). Version 1.32 for Windows. Laboratory of Plant Breeding, Wageningen University, Wageningen, the Netherlands.

4. Castle, A., Speranzini, D., Rghei, N., Alm, G., Rinker, D., and Bissett, J. 1998. Morphological and molecular identification of Trichoderma isolates on North American mushroom farms. Appl. Environ. Microbiol. 64:133137.

5. Chang, S. T. 1999. World production of cultivated and medicinal mushrooms in 1997 with emphasis on Lentinus edodes (Berk.) Sing. in China. Int. J. Med. Mushrooms 1:291-300.

6. Chen, X., Romaine, C. P., Ospina-Giraldo, M. D., and Royse, D. J. 1999. A polymerase chain reaction-based test for the identification of Trichoderma harzianum biotypes 2 and 4, responsible for the worldwide green mold epidemic in cultivated Agaricus bisporus. Appl. Microbiol. Biotechnol. 52:246-250.

7. Dodd, S. L., Crowhurst, R. N., Rodrigo, A. G., Samuels, G. J., Hills, R. A., and Stewart, A. 2000. Examination of Trichoderma phylogenies 
derived from ribosomal DNA sequence data. Mycol. Res. 104:23-34

8. Druzhinina, I., Kopchinskiy, A. G., Komon, M., Bissett, J., Szakács, G., and Kubicek, C. P. 2005. An oligonucleotide barcode for species identification in Trichoderma and Hypocrea. Fungal Genet. Biol. 42:813828.

9. Felsenstein, J. 1995. PHYLIP (Phylogeny Inference Package). Version 3.57c. Department of Genetics, University of Washington, Seattle.

10. Hermosa, M. R., Grondona, I., and Monte, E. 1999. Isolation of Trichoderma harzianum Th2 from commercial mushroom compost in Spain. Plant Dis. 83:591.

11. Kistler, H. C., and Leong, S. A. 1986. Linear plasmidlike DNA in the plant pathogenic fungus Fusarium oxysporum f. conglutinans. J. Bacteriol. 167:587-593.

12. Kopchinskiy, A., Komon, M., Kubicek, C. P., and Druzhinina, I. S. 2005. TrichoBLAST: A multilocus database for Trichoderma and Hypocrea identifications. Mycol. Res. 109:657-660.

13. Kullnig-Gradinger, C. M., Szakács, G., and Kubicek, C. P. 2002. Phylogeny and evolution of the fungal genus Trichoderma-A multigene approach. Mycol. Res. 106:757-767.

14. Lieckfeldt, E., Kullnig, C. M., Kubicek, C. P., Samuels, G. J., and Börner, T. 2001. Trichoderma aureoviride: Phylogenetic position and characterization. Mycol. Res. 105:313-322.

15. Mamoun, M. L., Savoie, J.-M., and Olivier, J. M. 2000. Interactions between the pathogen Trichoderma harzianum Th2 and Agaricus bisporus in mushroom compost. Mycologia 92:233-240.

16. Meyer, R. J. 1991. Mitochondrial DNAs and plasmids as taxonomic characteristics in Trichoderma viride. Appl. Environ. Microbiol. 57:22692276.

17. Muthumeenakshi, S., Brown, A. E., and Mills, P. R. 1998. Genetic comparison of the aggressive weed mould strains of Trichoderma harzianum from mushroom compost in North America and the British Isles. Mycol. Res. 102:385-390.

18. Muthumeenakshi, S., Mills, P. R., Brown-Averil, E., and Seaby, D. A. 1994. Intraspecific molecular variation among Trichoderma harzianum isolates colonizing mushroom compost in the British Isles. Microbiology
(UK) 140:769-777.

19. Ospina-Giraldo, M. D., Royse, D. J., Chen, X., and Romaine, C. P. 1999. Molecular phylogenetic analyses of biological control strains of Trichoderma harzianum and other biotypes of Trichoderma spp. associated with mushroom green mold. Phytopathology 89:308-313.

20. Ospina-Giraldo, M. D., Royse, D. J., Thon, M. R., Chen, X., and Romaine, C. P. 1998. Phylogenetic relationships of Trichoderma harzianum causing mushroom green mold in Europe and North America to other species of Trichoderma from world-wide sources. Mycologia 90:7681.

21. Park, M. S., Bae, K. S., and Yu, S. H. 2004. Molecular and morpho logical analysis of Trichoderma isolates associated with green mold epidemic of oyster mushroom in Korea. J. Huazhong Agric. Univ. 23:157-164.

22. Rigó, K., Varga, J., Tóth, B., Mesterházy, Á., and Kozakiewicz, Z. 2002. Phylogenetic analysis of Aspergillus section Flavi based on sequences of the internal transcribed spacer regions and the 5.8S rRNA gene. J. Gen. Appl. Microbiol. 48:9-16.

23. Samuels, G. J., Dodd, S. L., Gams, W., Castlebury, L. A., and Petrini, O. 2002. Trichoderma species associated with the green mold epidemic of commercially grown Agaricus bisporus. Mycologia 94:146-170.

24. Seaby, D. 1998. Trichoderma as a weed mould or pathogen in mushroom cultivation. Pages 267-287 in: Trichoderma and Gliocladium. Vol. 2. Enzymes, Biological Control and Commercial Applications. C. P. Kubicek and G. E. Harman, eds. Taylor and Francis, London.

25. Sinden, J., and Hauser, E. 1953. Nature and control of three mildew diseases of mushrooms in America. Mushroom Sci. 2:177-180.

26. Woo, S. L., Di Benedetto, P., Senatore, M., Abadi, K., Gigante, S., Soriente, I., Ferraioli, S., Scala, F., and Lorito, M. 2004. Identification and characterization of Trichoderma species aggressive to Pleurotus in Italy. J. Zhejiang Univ. Agric. Life Sci. 30:469-470.

27. Zhang, C. L., Druzhinina, I. S., Kubicek, C. P., and Xu, T. 2005. Biodiversity of Trichoderma in China: Evidence for a North to South difference of species distribution in East Asia. FEMS Microbiol. Lett. 251:251-257. 